\title{
Ladra, Trapaceira e Revisionista: a Representação da China como uma Ameaça e o Desencadeamento da Guerra Comercial Sino-Americana
}

\author{
Lucas Dantas ${ }^{1}$ \\ Rafaela Romano²
}

\begin{abstract}
Resumo
O presente artigo visa analisar como a guerra comercial entre EUA e China foi desencadeada por um processo de representação da China como uma ameaça, o que permitiu a Donald Trump tomar medidas excepcionais e fora das "regras do jogo" para, assim, iniciar sua campanha de taxações à China. Utilizando a teoria de Jutta Weldes sobre a produção da ideia de interesse nacional como fruto de representações intersubjetivas do "outro" e do "eu", pretendemos expor como a utilização de um discurso sobre a China, baseado na construção desse país como ladrão, trapaceiro e revisionista, permitiu a Trump se engajar em práticas comerciais que fogem da regularidade das normas internacionais. Esse processo contou com os movimentos de articulação e interpelação dessas representações à China, e permitiu a mobilização de apoio e afetos da população para que a guerra comercial emergisse. Finalmente, concluímos que essas representações já existiam no imaginário político estadunidense, e foram apenas realocadas pelo presidente a fim de iniciar o conflito comercial.
\end{abstract}

\section{Palavras chave: Estados Unidos - China - Guerra Comercial - Representações - Donald Trump}

\footnotetext{
${ }^{1}$ Graduando em Relações Internacionais no Instituto de Relações Internacionais da Pontifícia Universidade Católica do Rio de Janeiro. Email: lucasdantassouza@gmail.com.

${ }^{2}$ Graduanda em Relações Internacionais no Instituto de Relações Internacionais da Pontifícia Universidade Católica do Rio de Janeiro. Email: romanorafaela@gmail.com.
} 


\section{Abstract}

This article aims to analyze how the trade war between the USA and China was triggered by a process of representing China as a threat, which allowed Donald Trump to take exceptional and "outside the rules" measures in order to start his taxation campaign towards China. Using Jutta Weldes' theory about the production of the idea of national interest as the result of intersubjective representations of the "Self" and "Other", we intend to expose how the use of a discourse against China, based on the construction of that country as a thief, as a cheater and as a revisionist, allowed Trump to engage in trade practices that are against the regular international norms. This process involved the movements of articulation and interpellation of these representations towards China, and allowed the mobilization of support and affections from the population so that the trade war could emerge. Finally, we conclude that these representations already existed in the American political imagination, and were only relocated by the president in order to start the trade conflict.

\section{Key Words: United States - China - Commercial War - Representation - Donald Trump}

\section{Introdução}

Pela definição de Murdaco, uma guerra comercial é "um conflito entre Estados de natureza econômica em que um Estado aumenta tarifas sobre outro, seguido de pelo menos uma rodada de retaliação por outro Estado" (2016, p. 9). Nesse sentido, desde o início de 2018, Estados Unidos e China se engajaram em uma guerra comercial nunca antes vista entre os dois países, com taxações aos produtos um do outro as quais, em novembro de 2019, haviam chegado ao patamar de cerca de 1.623 bilhões de dólares (Thoms, 2019). De acordo com Naisbitt et al. (2019), os impactos desse conflito comercial na economia mundial serão grandes: as prospecções para 2020 e 2021 são de desaceleração econômica e, consequentemente, há uma propensão para que os níveis gerais de desemprego aumentam em diversos países (Amadeo, 2018).

Não é possível afirmar, entretanto, que essa guerra se iniciou repentinamente. A campanha de Donald Trump para a presidência dos Estados Unidos foi marcada por uma grande hostilidade à China, a qual seria responsável por "estuprar" os EUA com sua política econômica e comercial (Diamond, 2016; 
Wong \& Tong, 2019). Não foi a primeira vez que ele utilizou esse forte termo para descrever as relações sino-americanas, tendo feito isso também em 2011, em uma fábrica em New Hampshire (Diamond, 2016). Esses dois casos mostram que as implicâncias do republicano com a China são antigas ao ano de 2017, ano que, de acordo com Lu (2018), marcou o início dessa política de rivalidade com o país. Eles não explicam, no entanto, como Trump conseguiu chegar à Casa Branca com esse discurso. Não explicam, também, como tal discurso tomou as proporções de uma guerra comercial, ao invés de pontuais disputas comerciais, como comumente ocorria nas gestões Bush e Obama (Murdaco, 2016). Não explicam, finalmente, como policymakers, departamentos - como o de Comércio e o de Estado (Lu, 2018) - e tomadores de decisão aderiram fielmente a essa confrontação à China (e a justificativa vai além da mera submissão necessária desses funcionários ao presidente, como será visto posteriormente).

Por conta disso, uma análise pautada em aspectos apenas econômicos do desencadeamento da guerra comercial não nos possibilitaria responder - ou nos daria respostas limitadas a - perguntas pertinentes como "por que esse conflito saiu das disputas pontuais anteriores e tomou tamanha proporção"; "por que a guerra se iniciou em 2018, se os embates comerciais são antigos"; e "como parte da população se viu representada nos discursos anti-China de Trump, elegendoo e dando suporte para essa guerra". Desse modo, afirmamos que as justificativas para esse confronto, embora possuam alguma base em argumentos econômicos (base essa que será explicada posteriormente), não se restringem apenas a eles. Alegamos que a construção dessa guerra comercial passou, também, por um processo de representação da China como uma ameaça aos interesses nacionais americanos, processo esse que foi marcado, como será visto posteriormente, pela categorização da China como "ladra", "trapaceira" e "revisionista".

Com isso, o presente artigo objetiva analisar como discursos e representações adversas à China ajudaram a desencadear essa guerra comercial entre os dois países. Para isso, desenvolvemos como três circunstâncias - a desindustrialização americana e a ida das empresas para a China, o crescimento do poder econômico chinês e sua influência na economia global, e a postura chinesa de questionadora do status quo institucional em diversas organizações internacionais - foram utilizadas por Donald Trump não só como meio de se eleger mas também como forma de engajar burocratas, instituições governamentais, policymakers e a própria população em uma disputa comercial com os chineses nunca antes vista na história. 
Para isso, estruturamos esse artigo em cinco seções. Na segunda seção, realiza-se uma revisão teórica sobre as noções de interesse nacional e representação formuladas por Jutta Weldes. Com elas, nos será fornecido um arcabouço teórico e metodológico que nos permitirá analisar como esse conflito se iniciou a partir de construções de representações da China pelos EUA. Essas construções, como será visto, passam pelos movimentos de articulação e interpelação de características direcionadas tanto ao outro como a si mesmo, algo que será desenvolvido na seção.

Após isso, as três seções seguintes se debruçam em analisar as categorizações utilizadas por Donald Trump que permitiram ao presidente mobilizar o aparato governamental e os afetos da população para se engajar em uma guerra comercial com a China. Como será visto, isso foi possível por meio da classificação do país como ladrão (seção 3), trapaceiro (seção 4) e revisionista (seção 5), categorizações essas que não nasceram com o republicano, tendo sido elaboradas ao longo de gestões e governos anteriores e readaptadas por ele para justificar as tarifações e outras medidas protecionistas. Essas justificativas, por sua vez, se relacionam às ideias de Weldes sobre a construção do interesse nacional a partir de lógicas de representação do outro como uma ameaça, responsáveis por mobilizar apoio e afeto para promover agendas e interesses de representantes e governos, mesmo que esses sejam feitos "fora das regras do jogo" e a partir de medidas não-convencionais.

Por fim, reafirmamos na seção 6 a necessidade de se analisar a guerra comercial sino-estadunidense para além de seus aspectos econômicos, abordando também as questões políticas e socioculturais envolvidas no processo. Concluímos, assim, que as representações da China como ladra, trapaceira e revisionista por Trump, a partir dos movimentos de articulação e interpelação, permitiram mobilizar afetos e apoio para iniciar esse conflito comercial.

\section{Interesse Nacional e Representações}

A ascensão de teorias construtivistas e críticas nas Relações Internacionais a partir do fim da Guerra Fria (Guzzini, 2000, p. 147-150) ampliou consideravelmente as possibilidades de análise de fenômenos que acontecem no Sistema Internacional. Ao invés de atribuírem toda e qualquer ação dos Estados e de seus representantes a lógicas racionalistas e a interesses dados, os diferentes construtivismos e teorias críticas abordam essas ações como 
constructos sociais, que envolvem relações intersubjetivas ${ }^{3}$ entre diversos atores - como Estados, sociedade civil global e organizações internacionais - e diferentes objetivos, os quais vão além do mero interesse por poder (Guzzini, 2000).

Entre os autores construtivistas do campo das Relações Internacionais, Alexander Wendt foi o grande responsável por colocar a teoria construtivista no mainstream acadêmico, tendo buscado estabelecer uma "via média" entre as grandes teorias do campo ao conciliar uma ontologia voltada para o discurso e interpretação da realidade - que questiona a presença indubitável de uma realidade passível de ser objetivamente observada - com epistemologias e metodologias mais relacionadas à utilização do método científico tradicional (Wendt, 2014, p. 57-59). Nessa perspectiva, as teorias mainstream - Neorrealista e Neoliberal - seriam limitadas haja vista que tomam a realidade empírica como dada, e consequentemente, consideram características e interesses dos atores (majoritariamente, os Estados) como intrínsecos a eles, ignorando a possibilidade destes serem formados de maneira intersubjetiva (2014, p.52-54).

No entanto, uma semelhança que aproxima Wendt das teorias mainstream é o fato do autor, por conta dos objetivos de sua teoria, considerar que é possível teorizar sobre "interesses nacionais", tomando Estados como agentes unitários e monolíticos. Isso se deve ao fato de que, para o autor, essas unidades políticas são constituídas por instituições que permitem essa ação unitária (ou "ação coletiva") cujo conteúdo dela é determinado a partir da constituição da identidade do Estado. Nesse sentido, definindo identidade como "uma propriedade de atores intencionais que gera disposições motivacionais e comportamentais", ou seja, "uma qualidade subjetiva ou enraizada no autoentendimento de um ator" (Wendt, 2014, p 272), ele afirma que, nos Estados, há um processo de construção de uma identidade estatal baseada na atribuição a este de elementos constitutivos gerais (como uma língua e instituições comuns) junto a elementos co-constituídos, ou seja, formulados a partir das relações com outros autores, em uma lógica de SelfOther ${ }^{4}$. Dessa maneira, essa junção de características próprias dos atores com

\footnotetext{
3Intersubjetividade, aqui, é vista como uma "subjetividade compartilhada", uma individualidade consideravelmente influenciada pela estrutura social e pelos significados compartilhados pelos seus membros (Giddens, 1989). Nesse sentido, entendemos que o interesse nacional, fruto de um desenvolvimento próprio de cada Estado, é fortemente influenciado por concepções de interesse nacional compartilhadas entre os atores do sistema internacional.

4 Essa identidade estatal é formulada, como afirma, a partir de quatro tipos de identidade: (1) identidade corporativa; (2) identidade de papel; (3) identidade de tipo; e (4) identidade coletiva (Wendt, 2014, p. 272-282).
} 
aquelas formadas pela interação com outros atores define a sua identidade (2014, p. 272-282).

Ao definir como a identidade dos Estados - como atores monolíticos - é formada, o autor parte para teorizar sobre como suas ações, mediadas por seus interesses, são estabelecidas. Esses interesses, nomeados de "interesses nacionais" por ele, seriam uma mistura de características intrínsecas à formação da unidade política "Estado" - no caso, a busca por sobrevivência, autonomia, bem-estar econômico e autoestima coletiva - com aspectos relacionados a sua identidade e a sua relação com os outros atores (Wendt, 2014, p. 282-292). O que se percebe, com essa definição, é que o interesse nacional em Wendt ainda está relacionado com características inerentes à organização política do Estado, tal como feito pelas teorias mainstream, com a adição de um componente intersubjetivo que definiria as diferenças nas relações entre os atores no sistema internacional ${ }^{5}$.

A ideia de uma identidade monolítica ao Estado, na qual seus interesses e suas ações são majoritariamente definidos a partir de interações interestatais, foi questionada por diversos autores construtivistas. Jutta Weldes, autora cuja teoria nos servirá como base para esse artigo, acredita que esse movimento de unitarização da identidade dos Estados é prejudicial para a definição de seus interesses e, nesse sentido, para o entendimento de suas ações no sistema internacional. Isso porque, para ela, lógicas e estruturas internas aos Estados, que são reafirmadas ou questionadas por entidades individuais - especialmente agentes governamentais -, são ignoradas em detrimento de relações interestatais, que nem sempre são capazes de compreender os interesses e as identidades estatais (Weldes, 1996, p. 280). Por isso, a autora propõe um foco maior para essas lógicas internas dos Estados e como elas influenciam na determinação de identidades e interesses nacionais.

Nesse contexto, Weldes propõe outra definição para interesse nacional, que também leva em conta o papel de lógicas internas ao Estado e quem participa delas, como autoridades estatais. Como a autora analisa, a ideia de "interesse nacional" é fruto de uma construção social e intersubjetiva por parte dos atores do sistema internacional. Como define:

[...] interesses nacionais são construções sociais criadas como objetos de significado a partir dos significados intersubjetivos e culturalmente estabelecidos com os quais o mundo, particularmente o sistema internacional e o lugar do Estado nele, é entendido. Mais especificamente, os interesses nacionais emergem das representações - ou, para usar uma terminologia mais costumeira,

5 Para a explicação de Wendt sobre a diferença da sua concepção de "interesse nacional" para a das teorias mainstream (Wendt, 2014, p.288-292). 
das descrições de situações e das definições de problemas - através das quais as autoridades estatais e outros entendem o mundo ao seu redor (Weldes, 1996, p. 280, tradução e grifo nossos).

Com isso, Weldes faz três questionamentos quanto à constituição dessas "representações" que cita: (1) quem as constrói, (2) por que as constrói e (3) como as constrói. Para o primeiro questionamento, sua resposta é que, majoritariamente, são construídas pelos tomadores de decisão de política externa, mas podem ter outros atores envolvidos (Weldes, 1996, p. 281-282). Para o segundo, ela explica que tomadores de decisão precisam das representações como forma de se orientarem no sistema internacional e definirem o lugar de seu Estado nele (1996, p. 281-282). Para o terceiro, finalmente, podemos afirmar que as representações são construídas a partir de um arcabouço linguístico-cultural, mobilizado em dois processos: o de articulação e o de interpelação (1996, p. 281282).

Para entendermos o que são esses processos, devemos entender como eles são operacionalizados pelos atores, o que ocorre a partir de discursos. Um discurso, para Weldes \& Laffey, não é o mesmo que linguagem. Os autores definem discurso como estrutura e como prática. Como estrutura, "discursos são recursos socioculturais utilizados por pessoas na construção de significado sobre seu mundo e suas atividades", podendo eles também "utilizarem" as pessoas para sua concepção e reafirmação (Weldes \& Laffey, 2004, p. 28). Como prática, os discursos "são estruturas de significado em uso" (2004, p. 28). Dessa maneira, conclui-se que discursos são um conjunto de regras que possibilitam práticas ao mesmo tempo que são reproduzidas e/ou transformadas por elas. Além disso, discursos se manifestam tanto por práticas linguísticas, como também nãolinguísticas. Ademais, discursos são produtivos, isto é, produzem sujeitos e objetos e a relação entre eles. Por fim, discursos sempre estão envolvidos em instituições e são intrinsecamente políticos (2004, p. 28). Portanto, é possível compreender que discursos produzem condições de possibilidade para ações.

Os dois processos citados anteriormente - articulação e interpelação nos são necessários para a compreensão da definição de discurso como estrutura e prática. O movimento de articulação se refere ao processo de criação de sentido temporário a um objeto referente, através de recursos linguísticos. Esse objeto pode ser um líder de Estado, uma população específica, um objetivo geopolítico ou econômico etc. Muitas vezes, esses elementos mobilizados já possuem algum significado para as pessoas, podendo ele ser reafirmado ou modificado totalmente por pessoas em posição de autoridade, como tomadores de decisão, 
policymakers, líderes de Estado, grande mídia e outros atores. Com isso, a articulação inicia o processo de mobilização de elementos a fim de realocá-los sob a linguagem do interesse nacional, já que esse movimento reutiliza ou cria significados para justificar possíveis ações que serão executadas pelos tomadores de decisão (Weldes, 1996, p. 284-286).

Junto a isso, o movimento de interpelação é o processo em que identidades e, como efeito, os papéis específicos que essas realizam, são criadas a partir das relações sociais. Diferentes movimentos de articulação levam a diferentes identidades as quais, consequentemente, agirão de formas diversas e possuirão interesses distintos. Os indivíduos podem internalizar os significados a eles atribuídos e podem agir de acordo com a sua nova identidade. Logo, a interpelação gera o reconhecimento e a identificação com os sentidos atribuídos provenientes do movimento de articulação e, por consequência, essa passa a ter algum nexo com a realidade, correndo inclusive o risco de ser naturalizada pelos atores, isto é, de não ser percebida como algo construído socialmente (Weldes, 1996, p. 288-289).

É importante destacar que o processo de referenciação, que faz parte da interpelação, é intersubjetivo, ou seja, afeta tanto o referenciador quanto o referenciado. Nesse sentido, quando um ator é caracterizado com ameaça, implica-se que existe pelo menos algum outro ator sendo qualificado como ameaçado (Weldes, 1996, p. 287-289). Como será visto em nosso caso, por exemplo, há presente uma associação da China às palavras "ladra", "trapaceira" e "revisionista" por parte dos EUA, a qual esconde por trás um discurso que os define como ameaçados e vítimas dos vícios chineses, discurso esse capaz de mobilizar apoios e afetos por parte de representantes e instituições para que ações anti-China sejam tomadas. Portanto, a interpelação é responsável por criar dicotomias identitárias quase sempre baseadas na lógica de "Nós vs. Eles", lógica essa em que o "nós" é vitimizado ou enaltecido e o "eles" é incriminado ou desvalorizado. Isso, quando mobilizado sob a linguagem do interesse nacional, serviria para angariar apoio às ações dos tomadores de decisão, que nessa atribuição de papéis, ficariam com o de "heróis" e "salvadores".

Ressalta-se, no entanto, que essas representações não estão totalmente desassociadas da realidade empírica, com afirma Weldes (1996, p. 286-287). Na verdade, a escala de liberdade que os atores têm para realizar esse processo é constrangida consideravelmente pelo mundo empírico, servindo este como base para as interpretações dos atores. O exemplo de Purvis \& Hunt (1993, p. 482 apud Weldes, 1996, p. 286-287) sobre terremotos mostra isso: esse fenômeno ocorre 
independente de nossa consciência; porém, é a construção de discurso que determina se ele será um "movimento de placas tectônicas" ou "manifestações da fúria dos deuses". Dessa forma, a representação de um ator ou grupo de atores deve possuir algum fundamento na realidade empírica, o qual é mobilizado para sustentá-la.

Com isso, se queremos entender como a guerra comercial foi iniciada, devemos analisar o discurso ${ }^{6}$, enraizado em instituições governamentais estadunidenses, responsável pela formulação das representações, que foi mobilizado por Trump, políticos e policymakers para engajar apoio e afetos da população em nome dessa guerra comercial. Dessa maneira, identificaremos como elementos da realidade empírica foram manipulados para criar a representação da China como "ladra", "trapaceira" e "revisionista", gerando condições de possibilidade para deslocar as relações comerciais da escala da normalidade para fora das "regras do jogo", ou seja, para fora das normas convencionais de comércio internacional, representadas aqui pelo arcabouço jurídico, institucional e legal de organizações internacionais - em especial a Organização Mundial do Comércio (OMC) - que era responsável por nortear e regularizar padrões de conduta e comportamento entre os Estados (Murdaco, 2016). Dessa forma, poderemos analisar a emergência dessa guerra comercial para além de aspectos apenas econômicos.

\section{China: a "Ladra"}

Como dito na introdução, durante sua campanha para as eleições de 2016, Trump afirmou que os EUA não poderiam continuar deixando a China "estuprar nosso país, e isso é o que eles estão fazendo". Prosseguindo, afirmou que o que a China estava fazendo seria o "maior roubo na história do mundo" (Wong \& Koty, 2019). O presidente se referia, na ocasião, às práticas comerciais e econômicas que os chineses realizavam, as quais, como dirá posteriormente, seriam responsáveis por "fechar milhares de fábricas, deixando milhões de trabalhadores [americanos] desempregados" (TIME, 2016). Nesse mesmo discurso, Trump prossegue com críticas ao NAFTA e à entrada da China na OMC, que teriam, novamente, permitido esse "grande roubo de empregos" (TIME, 2016).

A campanha de Donald Trump foi fortemente marcada pela representação da China como uma ladra de empregos do povo americano, e como sendo uma

6 Para mais informações sobre o método de análise de discurso utilizado aqui, ler Laffey \& Weldes, 2004. 
das principais responsáveis ${ }^{7}$ pelos altos e crescentes índices de desemprego em regiões como o Rust Belt ${ }^{8}$, que afetou principalmente a classe de trabalhadores homens brancos, popularmente conhecidos como "rednecks". De fato, tais regiões foram fortemente impactadas pelo processo de desindustrialização provocado pela descentralização industrial a partir da década de 1970, com a ida de fábricas que, antes localizadas nos EUA, se direcionaram, principalmente, para a China (Tanskerley, 2016) - processo que ficou conhecido como China Shock ${ }^{10}$ (Autor et al., 2016).

Desde a década de 1970, temos uma China que mobilizou suas capacidades para entrar no jogo do capitalismo comercial global (Medeiros \& Geiger, 2016). Oferecendo matérias-primas e mão-de-obra a preços consideravelmente mais baixos que seus concorrentes regionais, a China disparou economicamente no final do século $X X$, iniciando o novo século como uma das maiores potências econômicas mundiais (Broomfield, 2003; Cable \& Ferdinand, 1994). Um país tão atraente para investimentos iria, consequentemente, atrair para si as principais indústrias globais, encantadas com a possibilidade de elevar seus lucros a partir da diminuição dos custos de produção.

Portanto, nota-se que realmente existe uma saída de indústrias dos EUA para a China. Esse fenômeno empírico, por sua vez, fora usado por Trump (especialmente durante as eleições), por meio do discurso, para representar a China como uma "ladra de empregos", representando o país como "ladrão" - por meio do movimento de interpelação e articulação - e, consequentemente, representando a identidade estadunidense como vítima das ações malignas chinesas, já que o movimento de interpelação é intersubjetivo. Essa representação gera a ideia de que os Estados Unidos são injustiçados e a China, por sua vez, é a injusta. Desse modo, ao colocar ambas as identidades dos países como opostas, passa-se a ideia de que seria impossível resolver um conflito entre ambos os países pelos meios usuais e, portanto, a única maneira de se solucionar

\footnotetext{
7 Ressalta-se que outros grupos, como os latinoamericanos - em especial os mexicanos - também foram responsabilizados pelo aumento do nível de desemprego, especialmente, entre os membros da White Working Class (ver Fortune, 2016 como exemplo).

${ }^{8}$ Rust Belt seria a região do Nordeste dos EUA, que incluiria os estados de Nova York, Pensilvânia, Ohio, Michigan, Indiana, Illinois, and Wisconsin. Esses estados teriam, a partir da década de 70, passado por processos de desindustrialização, os quais teriam gerado uma onda severa de desemprego e a sensação de abandono da população local (Abadi \& Gal, 2018).

"'Redneck" significa pescoço vermelho. O termo surgiu para se referir à classe trabalhadora branca (especialmente homens), em referência ao fato dessas pessoas ficarem durante muito tempo embaixo do Sol trabalhando, o que deixava seus pescoços queimados (e vermelhos). Não por coincidência, esse grupo foi fundamental para a eleição do atual presidente americano (Lee \& Morgan, 2018).

10 Choque Chinês, em português.
} 
esse problema seria por meio de uma guerra comercial. Percebe-se, dessa forma, como o interesse nacional foi criado a partir das identidades formadas pelo discurso reproduzido pelo presidente estadunidense.

Todavia, a representação da China como ladra pelos EUA não é fundamentada apenas pela saída das indústrias do território norte-americano. Segundo Daniel Kliman, diretor do Programa de Segurança da Ásia-Pacífico no Centro para uma Nova Segurança Americana, muitas empresas que passaram pelo China Shock em busca de diminuir seus custos de produção acabaram pagando um preço muito mais alto por isso, visto que a China as teria forçado a abrir mão de suas tecnologias e propriedades intelectuais para se unirem em joint ventures ${ }^{11}$ (Grossman, 2019). Existe, também, uma longa lista feita por agências policiais dos EUA de acusações contra indivíduos e empresas chinesas por hackear e espionar segredos comerciais de empresas que não têm sua produção localizada no território chinês (Grossman, 2019). O governo americano acredita que, nos anos de 2013 até 2017 , o valor total da propriedade intelectual roubada equivaleria à 1,2 bilhão de dólares (Grossman, 2019). Junto a tudo isso, existem pelo menos mil investigações em andamento sobre roubo de propriedade intelectual de empresas americanas que envolvem a China, segundo Christopher Wray, diretor do $\mathrm{FBI}$, que concedeu essa informação ao Congresso estadunidense (Grossman, 2019). Observa-se, portanto, que as práticas chinesas de joint venture e de desrespeito à propriedade intelectual foram vistas por membros do governo americano como, no mínimo, inadequadas, gerando uma série de problemáticas e processos judiciais contra a China.

Em concomitância com isso, um relatório de junho de 2018 do White House Office of Trade and Manufacturing (WHOTM) afirmou que essas ações e práticas do governo chinês fazem parte de uma estratégia industrial de longo prazo que visaria atingir a "dominação global". Para esse documento, o interesse nacional chinês seria que suas empresas substituam empresas estrangeiras como designers e fabricantes de tecnologias-chave e produtos, primeiro em seu próprio território, depois no restante do globo (WHOTM, 2018, n.p.). O documento prossegue afirmando que a China, a fim de alcançar seus interesses, possui duas grandes estratégias de agressão econômica: (1) adquirir tecnologias-chave e propriedade intelectual de outros Estados, incluindo os Estados Unidos; e (2) capturar as emergentes indústrias de alta tecnologia estrangeiras, as quais

11 Joint Ventures seriam acordos de cooperação entre duas empresas por determinado período, unindo recursos e negócios e dividindo os resultados. Nesse caso, isso permitiu que as empresas chinesas aprendessem mais sobre as tecnologias dos países centrais para, depois de alguns anos, começar a replicá-las em suas próprias empresas (Smith, 2019). 
guiarão o crescimento econômico nacional e os avanços na indústria da defesa do país. Ainda nesse relatório, há indicações de algumas formas pelas quais a China conseguiria realizar essas duas grandes estratégias, por meio de roubo de tecnologias e propriedade intelectual. Por fim, o documento encerra argumentando que, devido ao enorme tamanho da economia chinesa e à extensão de suas políticas e práticas de agressão econômica (focadas também nas tecnologias e propriedades intelectuais), a China representaria uma ameaça não apenas para os EUA, mas também para o mundo (WHOTM, 2018).

Essas ansiedades, portanto, demonstradas tanto pelo documento quanto pelas falas dos funcionários do governo estadunidense, indicam como há uma percepção generalizada de ameaça, relacionada a essas práticas de desrespeito à propriedade intelectual e de joint ventures, que seriam vistas como uma forma da China confrontar o poder americano e se afirmar como potência tecnológica e industrial. A frase que melhor explana isso é a do brigadeiro-general Robert Spalding, que afirma que "a China representa hoje uma ameaça existencial maior que o partido nazista da Segunda Guerra Mundial" (Grossman, 2019).

Donald Trump se utilizou dessas ansiedades para justificar suas ações excepcionais. A expulsão em 2018 da Huawei, empresa chinesa de tecnologia, é um exemplo disso. Como mostram Mascitelli \& Chung (2019), o argumento utilizado pelo presidente para fundamentar essa ação atípica foi o de perigo para a segurança nacional, baseado tanto nas práticas de quebra de propriedade intelectual que a empresa já praticou como no desenvolvimento da tecnologia de $5 G$ pela empresa, a qual poderia, na visão do governo, facilitar práticas de espionagem (Mascitelli \& Chung, 2019, p. 4). Não foi a primeira vez que o discurso de segurança nacional foi utilizado contra Huawei: em 2012, na gestão Obama, por exemplo, contratos entre o Estado americano e a empresa foram negados sob a justificativa de que seus executivos possuíam conexões próximas com o governo chinês, o que permitiria a troca de informações confidenciais entre eles. Outras empresas chinesas também foram vítimas desse argumento, como a Ralls Corp., que foi proibida de comprar quatro campos de energia eólica em Oregon por "perigo à segurança nacional" (Mascitelli \& Chung, 2019, p. 3). O que se observa na gestão Trump, entretanto, é uma exacerbação desse discurso da China como ladra e ameaçadora, na medida em que a expulsão da empresa possui uma série de implicações jurídicas e práticas para o governo e para a população (Mascitelli \& Chung, 2019, p. 3-5).

Desse modo, percebe-se que a existência de práticas de desrespeito à propriedade intelectual e de joint ventures foi mobilizada pelo presidente Trump a 
fim de representar a China como ladra (de tecnologias) e como ameaça (pelas acusações de espionagem), por meio dos movimentos de interpelação e de articulação. Temos, como consequência, a formação da identidade norteamericana como vítima e como ameaçada, por meio do movimento de interpelação, que é intersubjetivo. Dessa maneira, emerge uma definição de interesse nacional que clama pelo desrespeito das "regras do jogo", o que permite ações excepcionais como iniciar uma guerra comercial e expulsar grandes corporações de seus territórios.

\section{China: a "Trapaceira"}

Primeiramente, ideia de que a China seria uma ameaça econômica para os EUA não nasceu com a eleição de Trump. Como afirmam Ooi \& D'Arcangelis (2017) e Oliva (2019), a ideia da necessidade de "conter" ou cooptar a China remonta ao final do século XIX, época em que diversos missionários cristãos se aventuravam em jornadas ao Pacífico com o objetivo de disseminar a religião e o modelo de vida americanos para a maior população do globo na época (Oliva, 2019, p. 229). Havia, nesse período, uma série de estereótipos sinofóbicos ${ }^{12}$ relacionados aos chineses - taxados como "ardilosos, sorrateiros e imorais" -, emergente em um contexto de constante fluxo desse povo para os EUA. Isso foi visto pelos americanos como uma ameaça aos salários, à dominância e à estrutura familiar dos brancos, o que ficou conhecido como o "perigo amarelo" (Ooi \& D’Arcangelis, 2017, p. 273). Posteriormente, o perigo "amarelo" se transformou em perigo "vermelho" após a Revolução Chinesa de 1949, evento que ocasionou um congelamento das relações diplomáticas entre os dois países e o reconhecimento da Taiwan de Chiang Kai-shek como a única representante do povo chinês (Oliva, 2019, p. 229-230). As relações apenas seriam reatadas na gestão Nixon, que inaugura uma política de "contenção pela integração" com o país, a qual é seguida pelos presidentes posteriores (2019, p. 230).

Os engajamentos amistosos dos EUA pós-Nixon com a China seguiram, majoritariamente, essa lógica da "contenção por integração". Um dos mais proeminentes presidentes a fazer essa política foi Obama, que ineditamente inaugura uma política de "Asia First", com o objetivo de aumentar a influência estadunidense na região e conter o predomínio chinês local, sendo o maior exemplo disso o engajamento do presidente com a Parceria Trans-Pacífica,

\footnotetext{
12 Sinofobia é o medo ou aversão a chineses ou à cultura e modo de vida chineses.
} 
(Oliva, 2019, p. 231). Assim, seja a ida de missionários ou de presidentes, um medo da China crescer e se desenvolver sempre foi uma "paranoia" sustentada pelos EUA, seja como perigo amarelo ou vermelho.

Essa paranoia, relacionada com as ideias excepcionalistas por parte dos norte-americanos de que seu país deve sempre ter a primazia global em questões econômicas e militares para sentir seguro (Sachs apud Yu, 2019, p. 97), pode ser vista a partir das percepções da grande mídia sobre a "ascensão chinesa" a partir dos anos 2000. Uma análise realizada por Song et al. (2019), por exemplo, concluiu que o imaginário coletivo estadunidense comumente visualizou o crescimento econômico chinês como um perigo para os valores de democracia e liberalismo, seguindo uma lógica de "nós" vs. "eles" visto que os EUA comumente se autorreferem como protetores globais desses princípios (Bui, 2019; Song et al., 2019). De modo similar, Bui alega que a mídia estadunidense, baseada nos estereótipos sinofóbicos citados anteriormente - os quais classificam os chineses como "ardilosos, sorrateiros e imorais" -, se utilizou dessa perspectiva para condenar o crescimento econômico chinês e associá-lo com práticas de trapaça e deslealdade. $O$ resultado disso, como mostra o gráfico 1 referente à pesquisa realizada pela Gallup em 2014, é que o crescimento econômico chinês passa a ser encarado como uma ameaça pelo povo estadunidense.

Gráfico 1: "O quão preocupados estão os americanos em relação à economia chinesa?"

\section{Quão Preocupados estão os Norte-Americanos quanto à Economia Chinesa?}

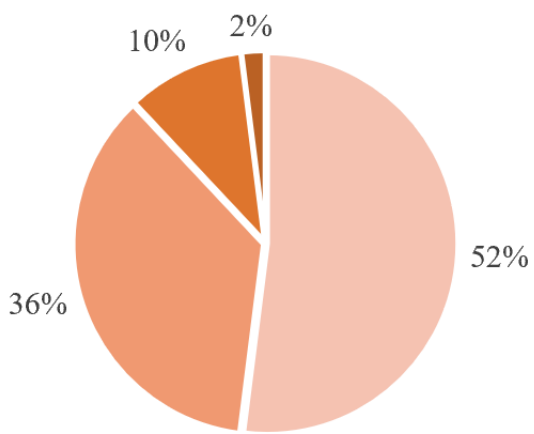

\footnotetext{
- Ameaça crítica para os interesses vitais estadunidenses no futuro

- Uma importante, mas não crítica, ameaça

- Não é uma importante ameaça

- Sem opinião
}

Fonte: Gallup, tradução nossa. 
Quanto à natureza empírica dessa representação, o principal argumento utilizado, tanto pela mídia quanto pelos líderes e representantes de Estado, para designar a alcunha de trapaceira para a China era que a desvalorização da sua moeda, o yuan, era a responsável pelos altos números de produtos exportados e, consequentemente, de crescimento registrados pelo país (Liew, 2010). De fato, as práticas comerciais chinesas podem ter sido voltadas para a desvalorização ao fim da década de 1990 e início dos anos 2000, visto que o país adotou medidas como a distorção do valor da moeda em dois - um oficial, mais caro, e outro para o "mercado"-; o atrelamento da moeda ao dólar a partir de 1995; e as tentativas para depreciá-la, tornando-a mais barata no mercado americano, o que era condenado pela OMC (Murdaco, 2016). Porém, a partir de 2005, tendo atrelado sua moeda a uma cesta de moedas e deixado o yuan apreciar, o argumento de que a China estaria desvalorizando sua moeda é, no mínimo, questionável, especialmente se consideramos o fato de que, em 2015, o FMl anunciou que pretendia colocar o yuan como moeda de reserva mundial, desqualificando consideravelmente as alegações de que a China possui práticas que depreciam sua moeda (Bui, 2019). Ademais, como dizem Ooi \& D’Arcangelis (2019, p. 273), não há um interesse do Partido Comunista Chinês (PCC) em desvalorizar o yuan pois o projeto econômico estatal busca um redirecionamento da economia chinesa para o crescimento doméstico, procurando aumentar o poder de compra de sua população. Dessa maneira, a insistência na representação da China como trapaceira pode ser vista, nesse contexto, como uma forma dos EUA justificarem a guerra comercial, enquadrando o crescimento chinês como o resultado de atividades ilegais e "fora das regras do jogo", devendo isso, portanto, ser respondido de maneira equivalente.

Outra fonte empírica de suporte para essa "paranoia" seria o fato de que os EUA possuem um déficit comercial enorme com a China, que totalizava quase 420 bilhões de dólares em 2018 (US Trade Department, 2019). O gráfico 2 mostra como houve um aumento considerável do prejuízo americano em relação à China ao longo da década de 2000. 
Gráfico 2: o déficit comercial estadunidense em relação à China

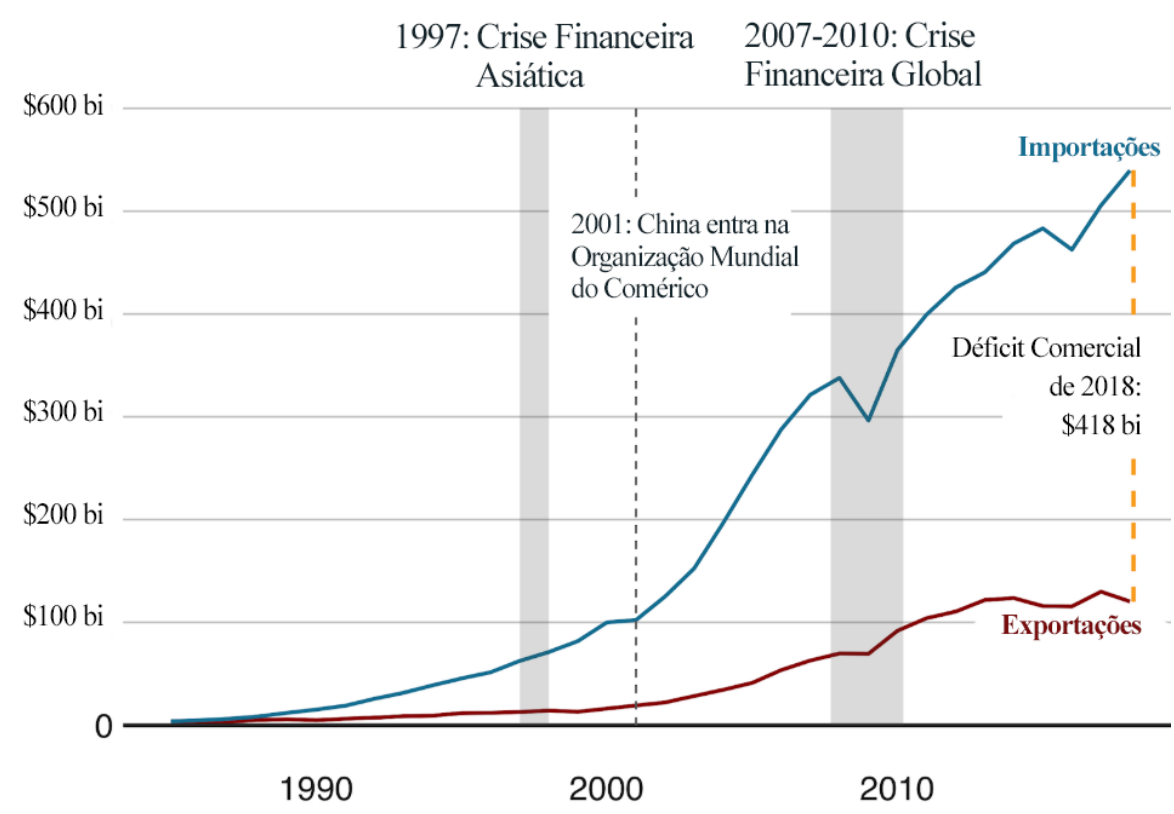

Fonte: BBC News, tradução nossa.

Resultado, principalmente, do processo de deslocalização industrial ocorrido ao longo da segunda metade do século $X X$, a China se tornou rapidamente a maior parceira comercial dos EUA, tendo aumentado consideravelmente suas trocas comerciais com os americanos a partir da sua entrada na OMC, em 2001, como mostra o gráfico 3. Isso foi utilizado por políticos estadunidenses como meio de validar ainda mais a proposição de que a China era trapaceira, visto que, nessa visão, o principal motivo do déficit seria a desvalorização cambial que o país realizava, o que tornava seus produtos mais baratos e, assim, mais atraentes para os compradores nacionais (LIEW, 2010). Um exemplo disso foi a mobilização orquestrada por senadores democratas, com apoio de Obama, para não só classificar a China como manipuladora cambial mas também impor direitos anti-dumping contra as importações vindas do país e instaurar um processo comercial contra ela na OMC (Liew, 2010, p. 656). Embora tenha recuado posteriormente, essa mobilização demonstra como o déficit comercial dos EUA com a China estimulou, em diversos momentos, a representação da China como manipuladora.

Como visto, o discurso da China como trapaceira não se iniciou com Trump, remontando ao século XIX com o "perigo amarelo" e sendo articulada na Guerra Fria e, depois, no período pós-Mao Tsé-Tung, quando o país inicia seu 
processo de crescimento econômico meteórico. Exemplos: Bush e Clinton chamaram a China de trapaceira (Murdaco, 2016, p. 167); o candidato republicano nas eleições de 2012, Mitt Romney, criticou Obama por não ter denunciado o país como "manipulador de moeda", prática que estaria sendo feita há anos e anos (Paletta \& Davis, 2012 apud Ooi \& D’Arcangelis, 2019, p. 272); diversas foram as discussões no Senado norte-americano, ao longo de 2015, sobre as práticas chinesas em relação a sua moeda, com exemplo do senador democrata Charles Schummer, que declarou que a China teria fraudado as regras por anos ao "ficar jogando" com sua moeda (Bradsher, 2015 apud Ooi \& D’Arcangelis, 2019, p. 272). Todos esses exemplos reforçaram, ao longo dos anos, a ideia de que a China cresce economicamente de maneira trapaceira e desleal. Isso, por sua vez, foi articulado por Trump em sua campanha presidencial, designando à China a identidade e papel de trapaceira e manipuladora e, para os EUA, o papel de vítima dessas práticas desleais, como mostra o seu discurso em 2016:

Então, como secretária de Estado, Hillary Clinton permaneceu à toa enquanto a China trapaceou em sua moeda, acrescentou outros trilhões de dólares aos nossos déficits comerciais e roubou centenas de bilhões de dólares em nossa propriedade intelectual [...] Vamos enfrentar trapaça comercial em qualquer lugar e em todo lugar que ameace um emprego americano. (FORTUNE, 2016, tradução e grifo nossos).

Dessa forma, Trump articulou as antigas categorizações da China e dos chineses como "trapaceiros" e "manipuladores", através de movimentos de articulação e interpelação. Dessa forma, por meio do movimento de interpelação, que é intersubjetivo, a identidade norte-americanos foi posicionada como ameaçada e injustiçada, permitindo assim, a criação de um interesse nacional e mobilização de apoio e afetos para a sua concretização. Se torna possível o engajamento na guerra comercial.

\section{China: a "Revisionista"}

Como visto anteriormente, os norte-americanos sempre desejaram levar seu modelo de vida para o Pacífico e integrá-lo ao sistema de capitalismo liberal que defendem (Oliva, 2019, p. 229). Após um longo período de congelamento das relações diplomáticas, com as reformas liberalizantes de Deng Xiaoping e com a consequente rápida expansão econômica chinesa, um clima tanto de otimismo quanto de pessimismo se instalava nos EUA (Cable \& Ferdinand, 1994).

Otimismo, pois, indicava que o país, antes a segunda maior potência do Bloco Socialista, estava progressivamente se direcionando para o lado capitalista. Pessimismo, pois, seu avanço era contínuo e avassalador, com altas taxas de 
crescimento econômico anuais e cada vez mais destaque nos mercados e no comércio globais, o que "ameaçaria", para muitos economistas, a hegemonia econômico-comercial estadunidense (Broomfield, 2003; Cable \& Ferdinand, 1994). Além disso, as práticas que a China exercia para alavancar seu crescimento econômico eram, para muitos, completamente destoantes do modelo neoliberal que emergia na época, com alto protecionismo e centralização da atividade econômica nas mãos do PCC (Broomfield, 2003; Cable \& Ferdinand, 1994), além das medidas de desvalorização de sua moeda que, como mencionamos anteriormente, eram vistas como "trapaça". Nesse contexto, muitos defendiam que, embora progressivamente encaixada no cenário global do capitalismo, a China precisaria se adequar mais às condutas liberais, ou seja, diminuindo o protecionismo e a centralização econômica e abrindo mais seus mercados.

Uma das "soluções" encontradas na época para readequar a China a essas normas liberais foi incluí-la em uma série de instituições intergovernamentais que imporiam ao país um conjunto de normas e regras de conduta de como agir no comércio mundial. Isso de fato ocorreu, o que é evidenciado pelo fato do país, desde 1966, ter entrado em cerca de 50 organizações intergovernamentais (OIGs) até o ano de 2000 (Kent, 2002, p. 344345). A entrada dos chineses na OMC, em 2001, por exemplo, foi vista de maneira positiva por países como os EUA, que acreditavam na adequação do país às normas liberalizantes do capitalismo global (Institute for Security \& Development Policy, 2018; World 101, 2019). O que ocorreu, porém, foi que a China além de não ter feito a descentralização desejada pelos EUA (World 101, 2019) tomou uma postura revisionista ${ }^{13}$ nas instituições internacionais, questionando as normas e ordens estabelecidas nestas que, majoritariamente, favoreciam os EUA (Grossman, 2019; Medeiros \& Gleiser, 2016). Nesse sentido, a adesão da China às organizações internacionais, ao invés de promover a liberalização de sua economia, não alterou muito a dinâmica de poder do país. Na verdade, pode-se afirmar que o país se fortaleceu com a entrada nas novas instituições internacionais, visto que avançou, nelas, sua agenda protecionista de desenvolvimento da economia (Grossman, 2019; Mascitelli \& Chung, 2019).

\footnotetext{
${ }^{13}$ Revisionismo, aqui, seria a "promover transformações nas regras do sistema internacional, nos processos de tomadas de decisão e/ou nas estruturas de cooperação multilateral, de forma a alcançar interesses e objetivos nacionais. As motivações do revisionismo chinês variam conforme o contexto. Na OMC, por exemplo, sua principal batalha era por maior participação e igualdade de peso dos países periféricos na organização (Medeiros \& Geiger, 2016, p. 59-60).
} 
Ressalta-se, também, que houve uma mudança de princípios na política externa chinesa após a entrada de Xi Jinping no comando do PCC. No início do século XXI, a retórica chinesa predominante era de "ascensão pacífica" no sistema internacional, adequando-se às normas e participando das instituições internacionais como meio de se tornar relevante nesse sistema ( $\mathrm{Li}, 2017$, p. 69). O revisionismo chinês passa a ser a característica predominante da sua política externa apenas com a entrada de Xi Jinping, em 2012, o qual a posição de "tomadora de normas" passa a competir com a de "modeladora de normas", com o país questionando parte ${ }^{14}$ do status quo nas organizações internacionais ( $\mathrm{Li}$, 2017, p. 69). Dessa forma, a posição mais protagonista e revisionista da China, caracterizada por essa mudança de política externa, fez com que países próstatus quo, como os EUA, temessem esses posicionamentos anti-sistêmicos.

Sobre a existência de um suporte empírico para essa representação, diversas são as críticas à ideia de que a China seria revisionista. Como afirmam Amigo (2019) e Glaser (2019), o revisionismo chinês é extremamente seletivo a algumas instituições e regras. Contudo, também são diversas as ações chinesas que se enquadram nessa ideia de subversão da ordem internacional. A emergência de grupos políticos como o BRICS e as propostas de contraposição a instituições como o FMl e o Banco Mundial (Zhang, 2015); a ideia de novas rotas de comércio e investimento na Ásia (Li, 2017); os questionamentos chineses em OIGs quanto ao menor poder de países emergentes e periféricos nesses locais (Medeiros \& Geiger, 2016); tudo isso foi visto como uma ameaça pelos formuladores de política externa e, portanto, seria necessário mudar a as abordagens direcionadas à China. Hillary Clinton, enquanto Secretária de Estado na gestão Obama, por exemplo, ficou conhecida por sua postura rígida em relação ao país, especialmente nos campos dos Direitos Humanos e na área de Defesa. Como disse seu biógrafo, Kim Ghattas, "a estratégia era trabalhar com eles no que [...] puder e contorná-los com a sociedade civil para promover sua agenda de valores" (Rauhala, 2015). Nota-se, portanto, uma necessidade dos formuladores de política externa americanos de ora se aproximar dos chineses, ora coagi-los a se adequar às normas e regras das organizações internacionais.

O discurso de subversão chinesa a ordem internacional foi articulado por Trump em 2017, quando ele a acusa de ser uma "potência revisionista do status quo global". Ao dizer isso ao mesmo tempo em que apresentava sua primeira

14 "Parte" do status quo pois a China varia seus posicionamentos a partir de seus interesses, variando entre o revisionismo e o "status-quonismo". Para mais informações, ler Amigo, 2019. 
National Security Strategy ${ }^{15}$ (Nagasawa, 2017), o atual presidente dos EUA enquadra as ações chinesas de revisionismo como ameaças à ordem global. Nesse relatório, Lu (2018) afirma que um grande foco foi dado a classificar a China como um país que "não segue as regras" e que opera como uma economia de "não-mercado" - justificando possíveis políticas especiais para lidar com ela - e à reconsiderar o apoio norte-americano à entrada do país na OMC.

O que se percebe aqui é que ao representar a China como essa potência revisionista, que não segue as regras, através dos movimentos de articulação e interpelação, os EUA também assumem a identidade de policial do mundo, por meio do movimento de interpelação, que é intersubjetivo. Ao formar a identidade dos países dessa forma, Trump consegue formular um interesse nacional e mobilizar afetos para justificá-lo. $O$ interesse nacional passa a ser um futuro posicionamento excepcional, posicionamento esse que se tornou, meses depois, a guerra comercial sino-americana.

\section{Conclusões}

Como visto, disputas comerciais, por mais que possuam argumentos de fundamentação econômica, podem ter justificativas de outras naturezas, como ameaças à segurança, hostilidade sociocultural e divergências ideológicas. Nesse sentido, observamos como, a partir da linguagem do interesse nacional, marcada principalmente pela produção de representações para os atores de um sistema, Trump conseguiu mobilizar um discurso da China como ameaça para iniciar uma série de taxações contra seus produtos, designando ao país as representações de ladrão, trapaceiro e revisionista, a partir de discursos, como meios de deslocar as relações comerciais sino-americanas para fora das "regras do jogo" e, assim, justificar essas taxações (e as possíveis consequências que viriam acompanhadas delas).

Observamos, também, que essas representações não foram criadas por Trump, mas sim, rearticuladas por ele. Como visto, há um forte histórico de inseguranças e ansiedades em relação aos chineses, que remonta desde o século XIX (com a ida de imigrantes chineses para os EUA), revivida após a Revolução Comunista e, depois, com o crescimento econômico estratosférico advindo das reformas liberais de Xiaoping, desembarcando no século XXI principalmente com

\footnotetext{
15 Ou "Estratégias de Segurança Nacional". Geralmente definem a postura dos EUA na política interna e externa, voltando-se, principalmente, para a área de segurança.
} 
a gestão Obama. Dessa forma, o que Trump fez foi reconduzir essas representações a fim de justificar sua política comercial hostil à China.

Os três fatores citados nesse artigo - o "roubo" de empregos e de tecnologia americanos, o ininterrupto crescimento econômico da China e o revisionismo chinês nas principais instituições internacionais - foram os ingredientes articulados para formar a receita da guerra comercial iniciada por Trump. A partir disso, a interpelação, o processo de designação de papéis e características a determinados atores, foi baseada nessas concepções de "ladra", "ameaçadora" e "revisionista". Para cada uma dessas concepções, Trump se afirmou no papel de contraponto e de possível protagonista-herói que seria responsável por conter esse temível país. À China ladra, Trump afirmou que traria de volta os empregos "roubados" dos norte-americanos, especialmente àqueles que sofreram com a desconcentração industrial do fim do século XX e com a ida dessas indústrias para países como a China e México - mas em especial à China (Fortune, 2016; TIME, 2016), ao mesmo tempo que afirmava uma política mais hostil em relação às joint ventures e empresas chinesas. À China ameaçadora, Trump prometeu confrontar o crescimento econômico chinês, o qual seria fruto de manipulação cambial, políticas protecionistas desleais e excesso de importações e acordos de livre-comércio (Fortune, 2016; TIME, 2016; Li, 2017). À China revisionista, Trump respondeu classificando o país como parte dos que "não seguem as regras", o que justificaria, posteriormente posturas e ações atípicas (Lu, 2018; Nagasawa, 2019;).

Com esse discurso, referenciando a China como o inimigo que deve ser neutralizado e se autodenominando como o único capaz de neutralizá-la, Donald Trump conseguiu mobilizar apoio suficiente da população para avançar sua agenda hostil à China, o qual teria como principais pontos a redução do déficit das relações comerciais com a China, a geração de novos empregos para os norte-americanos, o endurecimento em relação às práticas de joint venture com empresas chinesas e a confrontação ao revisionismo chinês.

Por fim, questionamos se os métodos empregados por Trump, tanto a mobilização do discurso anti-China como o engajamento em uma guerra comercial, foram as medidas mais apropriadas para lidar com problemas como desemprego e déficit comercial. Como mostra Naisbitt et al. (2019), a perspectiva de continuação da guerra comercial, visto que a China, também se sentindo ameaçada pelas tarifações americanas se engajou nesse conflito; produziu um clima geral de incerteza e insegurança no mundo, em relação à economia, o que terá como consequência a desaceleração econômica prevista para 2020-2021. 
Sob a defesa de que a América estaria ameaçada e, portanto, essas medidas eram necessárias, Trump pode ter, na verdade, produzido mais ameaça para seu país.

\section{Referências Bibliográficas}

ABADI, M.; GAL, S. The US is split into more than a dozen 'belts' defined by industry, weather, and even health. Business Insider, 2018. Disponível em: $<$ https://www.businessinsider.com/regions-america-bible-belt-rust-belt-2018-4>. Acesso em: 10 nov. 2019.

AMADEO, K. Trade Wars and their Effects on the Economy and You. The Balance, 2018. Disponível em: <https://www.thebalance.com/trade-warsdefinition-how-it-affects-you-4159973>. Acesso em: 22 nov. 2019.

AMIGO, C. China e cooperação Sul-Sul: caminho para o desenvolvimento ou novo imperialismo? Núcleo de Pesquisa em Desenvolvimento da PUC-Rio. Rio de Janeiro. 2019.

AUTOR, D. H.; DORN, D.; HANSON, G. The China Shock: Learning from LaborMarket Adjustment to Large Changes in Trade. Annual Review of Economics, Massachusetts, v. 8, ago. 2016, p. 205-240.

BROOMFIELD, E. V. Perceptions of Danger: The China Threat Theory. Journal of Contemporary China, v. 12, n. 35, 2003, p. 265-284.

BUI, L. T. Monetary Orientalism: Currency Wars and the Framing of China as Global Cheater. Global Society, Kent, 2019, p. 1-20.

CABLE, V.; FERDINAND, P. China as an economic giant: threat or opportunity. International Affairs, v. 70, n. 2, abr. 1994, p. 243-261.

DIAMOND, J. Trump: 'We can't continue to allow China to rape our country'. CNN, 2016. Disponivel em: <https://edition.cnn.com/2016/05/01/politics/donald-trumpchina-rape/index.html>. Acesso em: 04 dez. 2019. 
FORTUNE. Read the Full Transcript of Donald Trump's Jobs Speech. Fortune, 2016. Disponivel em: <https://fortune.com/2016/06/28/transcript-donald-trumpspeech-jobs/>. Acesso em: 22 nov. 2019.

GIDDENS, Anthony. A Constituição da Sociedade: esboço da teoria da estruturação. São Paulo: Martins Fontes, 1989, p.1-47.

GLASER, B. China as a Selective Revisionist Power in the International. Perspective, Singapura, v. 21, jan. 2019.

GROSSMAN, D. A preocupação nos EUA com o avanço da China: 'Uma ameaça maior que a União Soviética'. BBC, 2019. Disponível em: <https://www.bbc.com/portuguese/internacional-50392627>. Acesso em: $04 \mathrm{dez}$. 2019.

GUZZINI, S. A Reconstruction of Constructivism in International Relations. European Journal of International Relations, Londres, v. 6, n. 2, 2000, p. 147182.

INSTITUTE FOR SECURITY \& DEVELOPMENT POLICY. Breaking the Mould: Trump's China Policy. Focus Asia, 2018. Disponivel em: $<$ http://isdp.eu/content/uploads/2018/02/Trump-China-FA.pdf>. Acesso em: 04 dez. 2019.

KENT, A. China's International Socialization: The Role of International Organizations. Global Governance, v. 8, n. 3, 2002, p. 343-364.

LAFFEY, M.; WELDES, J. Methodological Reflections on Discourse Analysis. Qualitative Methods, Washington, D.C., v. 2, n. 1, 2004, p. 28-31.

LI, A. H. F. China Facing the Trump Presidency: Opportunities for Global Power Projection? China Perspectives, 2017, p. 69-73.

LIEW, L. H. US Trade Deficits and Sino-US Relations. Journal of Contemporary Asia, v. 40, n. 4, 2010, p. 656-673.

LU, F. China-US Trade Disputes in 2018: An Overview. China \& World Economy, v. 26, n. 5,2018 , p. $83-103$. 
MASCITELLI, B.; CHUNG, M. Hue and cry over Huawei: Cold War tensions, security threats or anti-competitive behaviour? Research in Globalization, n. 1, mai. 2019.

MEDEIROS, L. B.; GEIGER, L. M. China na Organização Mundial do Comércio: Revisionismo ou Status Quo? Século XXI, Porto Alegre, v. 7, n. 1, 2016, p. 48-60.

MORGAN, S. L.; LEE, J. Trump Voters and the White Working Class. Sociological Science, v. 5, abr. 2018, p. 234-245.

MURDACO, Barry F. The Hermeneutics of International Trade Conflicts: U.S. Punitive Trade Policy Towards China and Japan. 2016. 303 p. Dissertação (Doutorado em Filosofia) - The City University of New York, Nova York, 2016. Disponível em: https://academicworks.cuny.edu/cgi/viewcontent.cgi ?article $=1703 \&$ context=gc_et ds. Acesso em: 4 dez. 2019.

NAISBITT, B. et al. World Overview. National Institute Economic Review, 2019, p. 44-54.

NAGASAWA, T. Trump strategy brands China, Russia 'revisionist' powers. Nikkei Asian Review, 2017. Disponivel em: <https://asia.nikkei.com/Politics/Trumpstrategy-brands-China-Russia-revisionist-powers>. Acesso em: 04 dez. 2019.

OLIVA, M. Trump and China: Much Ado about Nothing. In: OLIVA, M.; SHANAHAN, M. The Trump Presidency: From Campaign Trail to World Stage. 1. ed. [S.I.]: Palgrave Macmillan, 2019, p. 227-247.

OOI, S.-M.; D'ARCANGELIS, G. Framing China: Discourses of othering in US news and political rhetoric. Global Media and China, v. 2, n. 3-4, 2017, p. 269283.

RAUHALA, E. Hillary Clinton's long - and complicated - relationship with China. The Washington Post, 2015. Disponivel em: <https://www.washingtonpost.com/news/worldviews/wp/2015/10/12/hillaryclintons-long-and-complicated-relationship-with-china/>. Acesso em: 22 nov. 2019.

SMITH, N. Trump Should Take Aim at China's Joint-Venture Rule. Bloomerang, 2019. Disponível em: <https://www.bloomberg.com/opinion/articles/2019-03- 
03/trump-should-pressure-china-to-drop-its-joint-venture-rule>. Acesso em: 22 nov. 2019.

SONG, Y.; LEE, C.-C.; HUANG, Z. The news prism of Nationalism versus Globalism: how does the US, UK and Chinese Elite press cover 'China's rise'? SAGE Pubications: Journalism, mai. 2019.

TANKERSLEY, J. How Trump won: The revenge of working-class whites. The Washington Post, $2016 . \quad$ Disponivel em: <https://www.washingtonpost.com/news/wonk/wp/2016/11/09/how-trump-wonthe-revenge-of-working-class-whites/>. Acesso em: 10 nov. 2019.

THOMS, A. Why trade wars have no winners. World Economic Forum, 2019. Disponivel em: <https://www.weforum.org/agenda/2019/11/who-benefits-from-atrade-war/>. Acesso em: 22 nov. 2019.

TIME. Read Donald Trump's Speech on Trade. TIME, 2016. Disponivel em: <https://time.com/4386335/donald-trump-trade-speech-transcript/>. Acesso em: 10 nov. 2019.

US TRADE DEPARTMENT. The People's Republic of China. Office of the United States Trade Representative, 2019. Disponivel em: <https://ustr.gov/countriesregions/china-mongolia-taiwan/peoples-republic-china>. Acesso em: 05 dez. 2019.

WELDES, J. Constructing National Interests. European Journal of International Relations, v. 2, n. 275, 1996.

WENDT, A. Teoria Social da Política Internacional. Apicuri: Editora PUC-Rio, 2014.

WHITE HOUSE OFFICE OF TRADE AND MANUFACTURING. How China's Economic Aggression Threatens the Technologies and Intellectual Property of the United States and the World. White House Office of Trade and Manufacturing. Washington, D.C. 2018.

WONG, D.; KOTY, A. C. The US-China Trade War: A Timeline. China Briefing, 2019. Disponivel em: <https://www.china-briefing.com/news/the-us-china-tradewar-a-timeline/>. Acesso em: 10 nov. 2019. 
WORLD 101. What Happened When China Joined the WTO? World 101, 2019.

Disponivel em: <https://world101.cfr.org/global-era-issues/trade/what-happenedwhen-china-joined-wto>. Acesso em: 20 nov. 2019.

$\mathrm{YU}, \mathrm{M}$. Introduction to the special issue on understanding the current China-U.S. 'Trade War'. China Economic Journal, v. 12, n. 2, 2019, p. 97-99.

ZHANG, M. What is China's role in the BRICS? World Economic Forum, 2015. Disponivel em: <https://www.weforum.org/agenda/2015/07/what-is-chinas-role-inthe-brics/>. Acesso em: 04 dez. 2019. 